\title{
Límites en el Espacio-Tiempo: retomando un debate.'
}

\author{
Boundaries in space-time: the re-opening of a debate
}

\section{Limites no espaço-tempo: A retomada de um debate}

\section{Rogério Haesbaert da Costa}

Geografo, Doctor en geografía humana, Posdoctorado en geografía

Profesor del Programa de Posgraduación en geografía de la Universidad Federal Fluminense

(Río de Janeiro, Brasil)

Email: riocult@yahoo.com

\section{RESUMEN}

Este artículo se propone analizar uno de los elementos constituyentes más importantes del territorio, el de sus límites o "fronteras". Partiendo del debate sobre la indisociable relación entre espacio y tiempo, considera los límites a través de su contextualización espacio-temporal y sin que éstos sean, a priori, interpretados como negativos, pues, nuestra existencia y nuestra autonomía dependen, constantemente, de la imbricación entre apertura y cerramiento, fijación y movilidad, o sea, creación y destrucción de límites.

Palabras clave: límite, frontera, espacio, tiempo.

\section{ABSTRACT}

This article proposes to investigate one of the most important constituent elements of territory, its boundaries or "frontiers". We begin from the debate on the inextricably relationship between space and time, by focusing on the boundaries through its space-time context. These boundaries are not interpreted, a priori, from a negative point of view - our existence and our autonomy depend constantly on the overlap between opening and closure, fixation and mobility, it means, creation and destruction of boundaries.

Key words: boundary, frontier, space, time.

\section{RESUMO}

Este artigo pretende analisar um dos elementos constituintes mais importantes do território, o de seus limites ou "fronteiras". Partindo do debate sobre a relação inseparável entre espaço e tempo, considere os limites através de sua contextualização espaço-temporal e sem que estes sejam, a priori, interpretados como negativos, porque nossa existência e nossa autonomia dependem, constantemente, da sobreposição entre abertura e fechamento, fixação e mobilidade, isto é, criação e destruição de limites.

Palavras-chave: limite, fronteira, espaço, tempo 


\section{Introducción}

En plena era de la llamada globalización se ha difundido ampliamente, sobre todo en los países centrales, la idea de un mundo cada vez más reticulado y fluido. Producto y, al mismo tiempo, condición para su reproducción de las relaciones de producción capitalistas, especialmente, bajo el modelo neoliberal, promovieron prácticas y discursos acerca de la fluidez, la "aniquilación del espacio por el tiempo" pregonada, aún, por el mayor crítico del capitalismo, Karl Marx. En palabras de David Harvey, "la perpetua reducción de las barreras espaciales es vital para el desarrollo capitalista de la acumulación" (1994: 230) que, para Deleuze y Guattari, da la impresión de que sus flujos "se dirigirían de buena voluntad hacia la luna, si el Estado capitalista no estuviera allá para reconducirlos a la tierra".(s/d[1972], p. 269).

Por otro lado, hoy pareciéramos vivir una gran paradoja, pues, al mismo tiempo que se difunde esta imagen de un mundo sin fronteras (por lo menos, aunque de forma relativa, para el capital financiero) nunca se construyeron tantos muros como en los últimos quince años, inclusive, entre fronteras internacionales. Especialmente, si examinamos a partir de la periferia mundial, tal vez, nunca habíamos estado envueltos en un rol tan diversificado y complejo de barreras o límites, desde fronteras amuralladas de centenares de kilómetros, hasta reductos más cotidianos como edificios y casas cercados, pasando por barrios donde el acceso, si no está completamente vedado, es cada vez más selectivamente controlado.

Recientemente, en visita a un proyecto social en una favela de Río de Janeiro, fuimos obligados a atravesar una barrera construida por una agrupación de narcotráfico, compuesta por dos anchos marcos de cemento cuya distancia difícilmente permitía el paso de un carro y cuya función, además de demarcar territorio ( $\mathrm{y}$, consecuentemente, manifestar poder) de un grupo, es impedir la circulación de vehículos mayores como el "caveirão"2 de la Policía Militar. En otras favelas, grupos paramilitares utilizan tácticas similares. A veces, la misma policía de las Ilamadas Unidades de Policía Pacificadoras (UPPs) en las favelas de Río imponen, no sólo un control espacial sino también temporal, prohibiendo a los moradores salir a la calle a partir de un determinado horario.

El toque de queda puede ser visto, en primer lugar, como una medida autoritaria formal que se reveló como una práctica, no sólo de muchos traficantes y paramilitares sino también de algunas policías, y que dio origen a movimientos de resistencia organizados como el Ocupa Borel y el Ocupa Alemán (este último, de actuación continua en la lucha contra la violencia policial en las favelas, especialmente, contra la población negra). En verdad, para la vida cotidiana en las barriadas pobres de muchas periferias latinoamericanas se trata, en la práctica, sinode una imposición más formal, sí de una especie de "Toque de queda" cotidiano que varía como la condición socio-económica, de género y de la banda etaria, que obliga a gran parte de la población a restringir brutalmente su movilidad y, muchas veces, a "enclaustrarse" en un pretendido espacio privado o "doméstico" que, no es raro, es violado por criminales o por la misma policía.

Impuesto de arriba hacia abajo de modo más formal, o insertado en la vida cotidiana como un instrumento de sobrevivencia (establecido por padres en relación a sus hijos, por ejemplo, previniéndose de la violencia), el toque de queda, en sentido amplio, es un dispositivo de poder que liga de tal forma tiempo y espacio, que puede ser tomado como un primer ejemplo a servir de inspiración para la discusión teórica subsecuente sobre la relación espacio-tiempo y la cuestión de los límites. Partiré del presupuesto, aparentemente banal, que controlar y delimitar el espacio implica también de alguna forma, controlar e imponer límites al tiempo.

Como si estuviésemos inmersos en distintos "toques de queda" envueltos en lo que

2. Caveirão es el nombre por el que se conoce popularmente el furgón blindado que utiliza la brigada de operaciones especiales (BOPE) de la policía militar de Rio de Janeiro [Nota del revisor]. 
DoreenMassey denominó múltiples geometrías de poder y que Yves Lacoste denominó espacialidades diferenciales, más que un espacio de movilidad y fluidez, vivimos hoy un mundo de flujos altamente selectivos y de controles temporales, moldeados por diversos intereses de orden no sólo económico sino también político y cultural - sin hablar de las modulaciones cada vez más exigidas, que se refieren, en sentido más estricto, a los flujos "ambientales" (aguas, vientos, desechos, etc.). Es de este modo que el debate geográfico contemporáneo exige, cada vez más, una especie de relectura de lo que entendemos por límites y/o fronteras territoriales.

En trabajos anteriores (Haesbaert, 2004 y 2014), intenté realizar un balance de las nociones corrientes y fortalecer una lectura renovada del territorio, visto siempre en una perspectiva dinámica, dentro del proceso, concomitante pero desigual, de (re)territorialización y desterritorialización. Inspirado en autores como Deleuze y Guattari (especialmente en sus obras "El Anti-Edipo" y "Mil Mesetas") y Raffestin (a su vez basado en Foucault), defendí un abordaje sobre el territorio que transcurre en una concepción también revisada de la relación espacio-tiempo. No había conseguido, con todo, detenerme con más énfasis en este que es uno de los elementos más importantes del territorio, el límite y/o frontera. Es este el debate que será aquí retomado.

\section{Sobre Espacio y Tiempo}

El toque de queda es un buen ejemplo para evidenciar que la imposición de una temporalidad -un horario-, debe también venir acompañado de una restricción espacial, en este caso, de constreñimiento a la circulación. Es prácticamente imposible definir una limitación temporal que no vaya acompañada de la definición de una circunscripción espacial de balizamiento. Delimitar el tiempo es, concomitantemente, una forma de delimitar también el espacio, y viceversa. Esto recuerda, de salida, el gran debate geográfico-histórico que liga regionalización y periodización, tan bien explicado por el geógrafo francés Christian Grataloup en sus artículos complementarios "Las regiones del tiempo" y "Los periodos del espacio" (Grataloup, 1991 y 2003).

Para Grataloup, cada conjunto de recortes regionales o, si queremos, de delimitaciones espaciales, que reconocemos y/o proponemos, esto es, cada proceso de regionalización, tiene una determinada duración temporal, o sea, tiene su validez restringida a un determinado periodo de tiempo, durante el cual la geografía se mantiene más o menos estabilizada. Lo mismo ocurre para los recortes temporales del historiador; sus periodizaciones siempre están, obligatoriamente, referidas a un determinado contexto espacial, a un recorte regional. Por ignorar las especificidades geográficas de cada región del mundo es que muchos historiadores eurocentrados extrapolaron, "exportando" una periodización claramente europea (principalmente la que distingue a las eras: Edad Antigua, Media, Moderna y Contemporánea) para todos los rincones del mundo. En síntesis, "para cada área (o región), una era (o periodo)".

Recortar el espacio y el tiempo significa, de una u otra forma, delimitar, concreta $y / o$ abstractamente, nuestro espacio-tiempo; en otras palabras y de modo bastante genérico, regionalizar y periodizar. Espacio y tiempo son vistos aquí como categorías gemelas, en la perspectiva defendida por diversos geógrafos entre quienes destacamos a David Harvey y Doreen Massey. Ambos trabajan con una perspectiva que rompe con la dicotomía que durante mucho tiempo separó espacio de tiempo; el primero, visto como fijación, estabilidad, o también, como "esencia duradera", "ser"; y el segundo, como cambio, dinámica o "devenir". Como afirmó Michel Foucault (1979), el espacio era tratado como "lo que estaba muerto, fijo, no dialéctico, inmóvil", frente a un tiempo tenido como "rico, fecundo, vivo, dialéctico" (p. 159).

Michel Foucault, siempre recordado cuando se habla de este cambio de perspectiva 
dominantemente temporal hacia una perspectiva de preponderancia espacial, afirma que pasamos de la "gran obsesión" por la historia, en el siglo XIX, hacia una época que "tal vez sea la época del espacio". La emergencia del espacio con tanta fuerza se está dando ${ }^{3}$ porque ahora estamos viviendo "la época de la simultaneidad", de la "yuxtaposición", "de lo cerca y lo distante", del lado a lado, de lo disperso" (Foucault, 1986: 22). Aunque debemos resaltar la cuestión de que la modernidad privilegió el tiempo sobre el espacio (sobre todo, a través de la idea del tiempo lineal y acumulativo de "progreso"), la cuestión crucial; según Grossberg (1996), es el tratamiento separado del espacio y del tiempo, incluso, a través de nomenclaturas como "estructura", más estable y fija, y "progreso", responsable de la dinámica y la transformación. Fue en este sentido, por ejemplo, que el historiadorFernandBraudel, en su gran y loable énfasis a la fundamentación geográfica en la historia, llegó en un momento determinado de su estructuralismo a posicionar el espacio geográfico - apropiado por él como "tiempo geográfico", de larga duración-, como el componente "de la fijación" y también del "retraso" de los procesos históricos, como si la geografía pudiera ser localizada en una temporalidad específica, casi única.

Los debates de los geógrafos anteriormente citados se sujetan, directa o indirectamente, a una amplia línea de filósofos que se extiende desde Leibniz, pasando por Newton, Kant, Heidegger y Merleau-Ponty. Cada uno a su modo, a través de determinado posicionamiento filosófico, (re)define espacio en su mayor o menor imbricación con el tiempo; o mejor, con la dimensión temporal de la realidad ${ }^{4}$. Vistos como "dimensiones" de lo social, espacio y tiempo no se reducen a categorías analíticas, sino que son vistos como constituyentes de las mismas prácticas sociales (o "percepciones", para los fenomenólogos). Como afirmó Merleau-Ponty:

\section{(...) la coexistencia que con efecto define}

el espacio, no es ajena al tiempo, ella es la pertenencia de dos fenómenos a la misma ola temporal. En cuanto a la relación entre el objeto percibido y mi percepción, ella no los liga en el espacio y fuera del tiempo: ellos son contemporáneos. La "orden de los coexistentes" no puede ser separada de la "orden de los sucesivos", o antes, el tiempo no es sólo la consciencia de la sucesión. La percepción me da un "campo de presencia" en el sentido amplio, que se extiende según dos dimensiones: la dimensión aquí-allí y la dimensión pasado-presente-futuro. La segunda permite comprender a la primera. [de modo más amplio, una permite comprender a la otra, agregaría yo] (Merleau-Ponty, 1999 [1945]: 357) ${ }^{5}$

Mientras algunos fenomenólogos resaltan el espacio como percepción subjetiva y/o enfatizan su dimensión corporal, individual, para un materialista como David Harvey, espacio y tiempo son, ante todo, construcciones sociales (Harvey, 1994). Inspirado en Henri Lefebvre (y también en Durkheim), él señala que no se trata de una proposición específicamente geográfica, sino que se proyecta ampliamente hacia otras ciencias sociales. "Decir que algo es socialmente construido", dice Harvey, "no significa que es subjetivo o arbitrario", y "la determinación de lo que es espacio y de lo que es tiempo no es políticamente neutra sino que está políticamente involucrada en una cierta estructura de relaciones de poder" (Harvey, 1994: 127). Por otro lado, es muy importante destacar, cada cultura elabora su propia concepción de tiempo y espacio y con ella, de algún modo, "se mueve". Así, dentro de una sociedad capitalista como la nuestra Harvey reconocerá nociones diferentes, por ejemplo, entre el espacio-tiempo del industrial y del inversionista en el mercado financiero. Espacio y tiempo son también "generalizados", distinguiéndose conforme al género al que están referidos, pues, hombres y mujeres acaban, de una u otra forma, construyendo sus propias

3. Decidimos cambiar el tiempo verbal de lo expresado en el texto original, pues, creemos que lo señalado por Haesbaert es un proceso que continua, no se ha detenido y aún, no es posible ver el final de ese camino ya que, a fin de cuentas, la historia, al decir de Hugo Zemelman, no es más que un dándose en un contexto territorial. (N.T).

4. Para un análisis más abarcante de esta "historia filosófica" de la categoría espacio, ver el trabajo de Casey (1997) que, aunque utiliza más el término "Iugar" ("place") antes que espacio, aborda, desde las perspectivas espaciales de Platón y Aristóteles, hasta las de Bachelard, Foucault, Deleuze y Guattari, Derrida e Irigaray

5. Los corchetes pertenecen al autor 
espacio-temporalidades.

Mucho más que un conjunto abstracto de líneas (o un "container" vacío a ser llenado), un mero juego de localizaciones de puntos o delimitación de áreas, el espacio debe ser visto a partir de su aspecto dinámico y sus distintas duraciones y, como diría Harvey (1994 y 2012), de su carácter relacional. Se trata de un conjunto de relaciones que no sólo revela conexiones "entre" espacios -resaltado en la condición de espacio relativo-, sino una vinculación intrínseca a la misma configuración de esos espacios -la relación como constituyente inherente a la espacialidad. Según Harvey, reuniendo elementos del idealismo de Leibniz y del realismo de Whitehead, en un abordaje relacional "cada proceso produce su propio espacio y tiempo" (1994: 129), y la cuestión básica al contrario del espacio absoluto, es que el espacio y tiempo no pueden tener existencia independiente, separada de los procesos que los producen. Harvey llega entonces a la especificidad del espacio-tiempo capitalista, indicando que el capitalismo revolucionó el espacio y el tiempo al redefinirlos constantemente de acuerdo a sus nuevas exigencias y necesidades.

Así, aquello que en una geometría más simple, euclidiana, es leído como espacio-punto, se transforma automáticamente en espacioconexión, las líneas son rellenadas por flujos, asimismo, las extensiones o zonas no sólo son constituidas (o "contienen") redes en movimiento sino también, en conjunto, se movilizan -como en la metáfora de la mancha de aceite o en la realidad de una masa de aire- que se desplaza y se transforma. El espacio, así, se torna sobre todo fruto de conexiones y, además de eso, incorpora de forma indisociable el juego entre los mundos material y mental, superando otra dicotomía que ve el espacio sólo como materialidad, "exterior", y al tiempo como incorpóreo, "interior". Más que la estabilidad de un "ser", el espacio envuelve el constante "tornarse" (otro). De este modo, inspirado en los filósofos Deleuze y Guattari, Lawrence Grossberg (1993) afirma:
Es una cuestión de geografía del devenir [becomings], una pragmática de lo múltiple. (...) Devenir es la espacialización de la transformación; él se rehusa, no solamente a privilegiar el tiempo sino a separar a espacio y tiempo. Es una cuestión de temporalizar el espacio y de espacializar el tiempo. (...) Deleuze y Guattari toman la realidad como siendo tanto real (productiva) como contingente (producida) -realidad produciendo realidad-y la producción de la realidad es la práctica del poder: Realidad no es nada sino efectos que pueden ser medidos solamente como líneas, no puntos (p. 181). ${ }^{6}$

DoreenMassey (2008) contribuye decisivamente a esta relectura al proponer el espacio como un conjunto o un tramado de trayectorias; o mejor aún, de historias, impregnando el espacio de la densidad temporal que lo compone. Densidad temporal que no se reduce a la materialidad relativamente fija ("historias enterradas", diría ella) de una "acumulación desigual de tiempos" -en términos de Milton Santos-, sino que se expande en el sentido de una dinámica temporal que está siendo constantemente remodelada y reconstruida por los múltiples pasajes que no sólo "cruzan" el espacio sino que continuamente lo rehacen.

Así, el espacio no es un "collage de lo estático", dirá Massey, sino un haz de trayectorias siempre en proceso. El espacio, al mismo tiempo que puede interferir, en un lenguaje braudeliano, "retardando la historia", también puede, al contrario, acelerarla, pues, su permanente apertura (o no) para la realización de nuevas trayectorias es condición fundamental para que una nueva historia pueda ser producida. Espacio, así, es resultado e inductor de la multiplicidad que compone a la transformación social. Es en este sentido que el espacio es también la dimensión del reconocimiento de lo Otro, un otro que no está "atrás" (temporal o espacialmente) sino que se encuentra, respetada su propia trayectoria, de nuestro lado.

6. En el original: "It is a matter of a geography of becomings, a pragmatics of the multiple". (...) "Becoming is the spatialisation of transformation; it refuses, not only to privilege time, but to separate space and time. It is a matter of the timing of space and the spacing of time. (...) Deleuze and Guattari take reality to be both real (productive) and contingent (produced) reality producing reality - and the production of reality is the practice of power. Reality is nothing but effects which can be measured only as lines, not points" 


\section{Sobre Límites y Fronteras}

De una u otra forma, variable de acuerdo a cada momento histórico y cada contexto geográfico, acabamos siempre estableciendo algún tipo de límite, de frontera entre grupos, clases, individuos. Es bien conocido el amplio debate iniciado, sobre todo, en el área de la Geografía Política, sobre límites y fronteras. Machado (1998) nos recuerda que frontera, cuya etimología sugiere "lo que está enfrente", en su origen, no estaba relacionada al concepto legal o político-administrativo al que hoy aparece predominantemente asociado. La frontera, de este modo:

nació como un fenómeno de la vida social espontánea, señalando la imagen del mundo habitado. En la medida que los modelos de civilización se fueron desarrollando por encima del nivel de subsistencia, la frontera entre ecúmenos se tornaron lugares de comunicación y, por consiguiente, adquirieron un carácter político. Asimismo, no tenía la connotación de área o zona que marcara el límite definido o final de una unidad política. En realidad, el sentido de frontera no era el de fin sino de comienzo del estado, el lugar hacia donde él tendía a expandirse. (p. 41). ${ }^{7}$

Así, aparece hoy la noción de "frontera socioeconómica" o también "de poblamiento" como queda claro, por lo menos, desde el clásico trabajo de Frederick Turner sobre la frontera norte-americana (Turner, 2004 [1893]). Para Turner, la misma frontera norte-americana - en su interpretación, una frontera "de la civilización"constituyó la gran referencia para la constitución de la nacionalidad de los Estados Unidos ${ }^{8}$. Deleuze y Guattari (s/d [1972]), se refirieron al "sentido americano" de frontera como "algo a superar, límites a franquear, flujos a ser pasados, espacios no codificados para penetrar (p. 232), típico del proceso de desterritorialización inherente a la reproducción capitalista.

El geógrafo Porto-Goncalves (2002), por su parte, destaca una analogía interesante de la frontera como "front", locus de luchas y disputas, tanto en el sentido interno como en relación al exterior:

Las fronteras comportan el front y traen consigo, siempre, la memoria de las luchas que las engendraron. Por tanto, más que el espacio absoluto de los territorios soberanos de los Estados modernos [y sus líneas limítrofes rígidas] destacamos su carácter abierto (poroso) y contradictorio, tanto en el front interno como en el front externo. Hay, siempre, detrás de lo instituido el proceso instituyente $\mathrm{y}$, en el caso de la frontera, el límite explica su carácter esencialmente político. (p. 351-352).

El límite, en relación a la frontera, tiene una connotación más explícita. Cuando recordamos su origen romano, en los "limes" que delimitaron el alcance de los dominios del Imperio, muchas veces fijados por muros; queda muy claro su papel definidor de un "fin" político-administrativo. Machado (1998) resalta esta distinción entre límite y frontera:

La frontera está orientada hacia afuera (fuerzas centrífugas), mientras que los límites están volcados hacia adentro (fuerzas centrípetas). Mientras la frontera es considerada una fuente de peligro o amenaza porque puede desarrollar intereses distintos a los del gobierno central, el límite jurídico del Estado es creado y mantenido por el gobierno central, no teniendo vida propia y tampoco existencia material, es un polígono. (p. 42).

Hissa (2002), a su vez, asocia el límite, como en la naturaleza, a una abstracción:

(...) el concepto de límite es propio de la cultura de los pueblos. La naturaleza física así definida por los "ojos de la cultura", no establece guardianes de fronteras y tampoco establece límites de forma deliberada. En la naturaleza, el límite es un elemento intruso, idealizado. (...) todo lo que puede ser comprendido como propio de los dominios

7. Las negritas son de la autora.

8. Para un análisis comparativo entre la formación territorial brasilera y norte-americana, a partir de esta idea de "frontera (socio-económica) en movimiento", ver el trabajo del antropólogo Octavio Velho (1979). 
de la naturaleza desconoce el límite y su propia existencia. (p. 20-21).

Para este autor, la frontera también está hecha de un "espacio abstracto", por tanto, irreal, "por donde pasa el límite" (Hissa, 2002: 34). Frontera, geográficamente hablando, envuelve siempre, por tanto, un área o zona (lo que torna el término "zona de frontera" un tanto redundante), y parece indicar más un comienzo, en tanto que el límite es representado por una línea y "parece significar el fin de lo que establece la cohesión del territorio" (Hissa, 2002: 34). Esto no significa, sin embargo, que no sea amplio el debate en torno de su intersección, hasta porque en el sentido común, su uso como sinónimo es bastante difundido. Aunque el límite estimule "la idea sobre la distancia y la separación" y la frontera incite a pensar "sobre el contacto y la integración", la distinción entre los conceptos envuelve un "espacio vago y abstracto". (Hissa, 2002: 34).

Límites, de cualquier modo, son componentes indisociables de las fronteras, especialmente, cuando estas son definidas priorizando su connotación política9 ${ }^{9}$ Si el límite trabaja obligatoriamente con alguna idea de fijación, la frontera envuelve, sobre todo, la concepción de movimiento y transformación del espacio. En un mundo tan móvil como el nuestro, hoy, es claro que estas distinciones, como veremos más adelante, deben ser problematizadas

El sociólogo José de Souza Martins enfatizó la perspectiva conflictiva y espacio-temporalmente situada de la frontera en su libro "Frontera: la degradación del Otro en los confines de lo humano", cuestionando la visión idealizada de la frontera como "frente pionero" donde el colonizador es visto como el "supuesto héroe creador", modernizador y transformador de la sociedad. Así, afirma el autor:

(...) lo aparentemente nuevo de la frontera es, en verdad, expresión de una complicada combinación de tiempos históricos en procesos sociales que recrean formas arcaicas de dominación y formas arcaicas de reproducción ampliada del capital, inclusive, la esclavitud, bases de la violencia que la caracteriza. (...) Las concepciones centradas en la figura imaginaria del pionero dejan de lado lo esencial, el aspecto trágico de la frontera, que se expresa en la mortal conflictividad que la caracteriza, en el genocida desencuentro de etnias y en el radical conflicto de clases sociales. (...) (Martins, 1997: 15).

Si la frontera puede representar una especie de vanguardia que nos impulsa hace el frente, en el rumbo de lo nuevo, convocándonos a trasponer los límites, nada garantiza que esto nuevo y que esta trasposición sea sólo o sobre todo, positiva. Al revés de sólo "frente" o "inicio", ella incluye también un fin, o por lo menos, un "con-fin" donde lo mismo y lo Otro acaban inexorablemente, se encuentran o se desencuentran, como destaca Martins. Es en este doble sentido de "front", en tanto espacio de lucha, de avance y de innovación, y al mismo tiempo, de la contención, de la retención y de la permanencia, y así también, del conflicto, como enfatiza Martins, que encontramos la "verdadera" frontera y los límites de la frontera.

Se percibe ahora, cuánto el debate entre límites y fronteras tiene que ver con la cuestión más amplia del propio espacio y su relación indisociable con el tiempo. Observar el límite es mirar también hacia las limitaciones de nuestras concepciones de espacio. Delante del límite como línea y fijación, vuelto hacia un "dentro" precisamente definido, corremos el serio riesgo de permanecer en una visión muy restringida de espacio absoluto, de una coexistencia sin flujo, estática, donde cada espacio que el límite separa es enfatizado en sus propiedades independientes, como si cada territorio -estatal, por ejemplo- pudiera ser leído sólo por sus singularidades (geográficas, lingüísticas, étnicas...), olvidándose que con frecuencia son esos mismos límites, al principio abstractos, los que forjan esas especificidades. Más que la estabilidad de un "ser", el límite puede ser visto, ante todo, por la transformación de un constante "venir-a-ser". En los términos de Hissa (2002): 
El límite anhela la precisión y se insinua como un muro, pero contradictoriamente, a través de la frontera, se presenta como transición, como mundo del permanente venir-a-ser y de la ausencia palpitante. En estos términos, ¿cómo pensar la frontera como demarcación entre dominios?(p. 35).

El filósofo Heidegger destaca en el límite no su carácter de fin, donde algo termina sino, "como habían observado los griegos, aquello a partir de lo cual alguna cosa comienza a ser (seinWesenbeginnt)". Por otro lado, el mismo espacio, dirá él, "es esencialmente lo que fue 'ordenado' ['arrumado'], lo que se hace entrar en su límite". (Heidegger, 2006 [1954]: 183) ${ }^{10}$. Estas constataciones traen a la superficie el carácter espacial ambiguo del límite, al mismo tiempo que indica menos un término y más una emergencia, un "venir-a-ser", él demuestra que todo arrumar del espacio -o, como preferimos, toda des-articulación (con guión) espacialimplica alguna forma de ordenamiento, de orden espacial, por más precaria o desarticulada que parezca.

Límite, por tanto, no puede ser visto sólo como marcación de diferenciasy separación, control de la movilidad y segregación. Cuando Hissa (2002) afirma que "tal vez el significado más decisivo de límite sea el que inmediatamente conduce a la idea de cercenamiento de la libertad", propuesto como "obstáculo al libre tránsito", aquello que "se pone a vigilar el territorio y el dominio prohibidos", despertando "la noción de propiedad" (p. 19), debemos tener cuidado para no incurrir en el equívoco de ver límite en un sentido estrecho y exclusivamente negativo. Hasta porque, en un sentido amplio, nuestra vida puede ser vista como desdoblándose en un ir-y-venir entre aperturas y cierres, fijaciones y movilidades; en otras palabras, creación y destrucción de límites. Como se trata de dimensiones geminadas, "cierre" y "fijación" serán siempre, está claro, relativos, o más aún, relacionales, pues, la relación mutua no sólo debe ser reconocida entre estos procesos sino también en la constitución interna de sus producciones, de los órdenes espaciales de allí advenidos.

\section{Sobre Límites en el Espacio-Tiempo contemporáneo}

Hoy, más que en otros tiempos, con el avance tecnológico y los cambios político-económicos que aceleran flujos de todo orden -creando toda una geometría espacial de poder compleja y desigual, emerge con mucho más fuerza la discusión de los "límites"- límites como restricción, contención, en una connotación negativa, pero también en un sentido de construir parte indisociable de nuestra dinámica civilizatoria, en la medida que, biopolíticamente hablando, el modelo societario hegemónico, basado en la acumulación y/o en el "crecimiento" capitalista, puso en juego igualmente, nuestra sobrevivencia en tanto especie biológica sobre la tierra.

No se trata, con todo, de la ilusión modernista de límites y segmentaciones espaciales claras, como ocurría en las sociedades disciplinares clásicas a través del mito de la individualización funcional de los espacios que a todo/a todos debería ordenar. Las sociedades actuales, aunque difícilmente puedan ser caracterizadas de modo genérico, son vistas como "sociedades de control" -en el sentido de control como "verificación" (Deleuze, 1993)- o como "sociedades de seguridad" (Foucault, 2008). No hay duda, sin embargo, que la inseguridad se transformó en un "modo de gestión de la vida colectiva" (Rancière, 2003) y que el capitalismo se manifiesta igualmente como un "capitalismo de desastre", generador de crisis (Klein, 2008). La crisis, que ya Milton Santos identificaba como definidora ella misma de una era y no como una transición entre periodos, es vista hoy como condición a ser "administrada", inherente a lo que sería nuestra reproducción en tanto sociedad, y no como una situación a ser efectivamente combatida. En palabras de Giorgio Agamben 
(2013), “...no sólo en la economía y en la política, sino en todos los aspectos de la vida social, la crisis coincide con la normalidad y se torna, de este modo, sólo una herramienta de gobierno".

Agamben, remitiendo a Foucault cuando éste establece la idea moderna de seguridad en las propuestas de Quesnay durante el "Antiguo Régimen", afirma que el "axioma de la gobernabilidad moderna" se vuelve la máxima" ya que gobernar las causas es difícil y caro, es más seguro y útil intentar gobernar los efectos" (2013, versión on line). La gran meta de la política contemporánea es, por tanto, controlar los efectos, lo contrario de atacar y dominar a las causas. Con esto es posible evidenciar la correspondencia contradictoria entre "un paradigma económico absolutamente liberal" y un "paradigma de control policial y estatal sin precedentes e igualmente absoluto". Esto, en verdad, nos ayuda a comprender la paradoja señalada al inicio de este texto, entre un mundo de ruptura de límites y fronteras para fracciones del gran capital y restaurador de barreras y controles fronterizos, especialmente en el "Estado policial" instaurado para vigilar refugiados y migrantes pobres. Así, "si el gobierno apunta a los efectos y no hacia las causas, está obligado a extender y multiplicar el control [verificación y cálculo de "riesgos", de probabilidades]. Las causas exigen ser conocidas, mientras que los efectos sólo pueden ser verificados y controlados" (Agamben, 2013, versión on line).

Foucault (2008) nos advierte acerca del hecho, que en las sociedades de seguridad -también denominadas sociedades biopolíticas ${ }^{11}$ - la gran cuestión es el control de lo que él denomina "medio", el espacio en el que se da la circulación. La movilidad, los flujos, en sus distintas modalidades, tanto de elementos humanos como no-humanos, se torna un objeto central de la política ${ }^{12}$. Así, al contrario de los límites espaciales más rígidos y cerrados propuestos por la reclusión disciplinar, tenemos lo que he denominado procesos de contención territorial (Haesbaert, 2014), más dinámicos y ambiguos, donde termina prevaleciendo un efecto "represa" y/o de "canalización", mucho más que de reclusión (cerramiento por todos lados). Foucault habla de un proceso selectivo de movilidad, separado y monitoreando las "buenas" y "más" circulaciones. Así, podemos afirmar:

Nuestro tiempo, (...) lejos de ser un tiempo "sin límites" -que sería en última instancia un "tiempo sin espacio", destituido de todo territorio y frontera- es un mundo que, tal vez, acoja la mayor diversidad de manifestaciones territoriales ya conocida en la historia humana $\mathrm{y}$, contradictoriamente, el que vive el mayor riesgo de pérdida de esa diversidad. De allí la frecuencia con que se rehacen límites, se reconstruyen fronteras, pero igualmente en beneficio de los modelos impuestos y/o defendidos por los grupos hegemónicos e involucrando disputas internas de fracciones de la clase dominante. Se juega todo el tiempo con los (nuestros) límites, tanto en el sentido de redefinir líneas y zonas demarcadoras, como de redireccionar, acelerando o retardando flujos. (Haesbaert, 2014: 299).

Agamben resalta que, hoy, el mismo "Estado de seguridad", sometido "al signo de seguridad" y abandonando el dominio de la política, "entró en una tierra de nadie, cuya geografía y fronteras son aún desconocidas". Esto genera una preocupación extrema "sobre los peligros que representa para la democracia, porque en él se vuelve imposible la vida política y democracia significa, precisamente, la posibilidad de una vida política". En más de un sentido, recordando

11. Para el debate sobre lo que denomino "sociedades biopolíticas de in-seguridad" y el "des-control de los territorios" allí involucrados, ver Haesbaert, 2014, especialmente en Capítulo 6.

12. Para el debate sobre movilidad en geografía, ver Creswell (2006).

13. Límites que, según el autor, son definidos por un -para todos- en la tiranía; por pocos, en la oligarquía, y por todos -para todos los ciudadanos- en la democracia. "Así, para los griegos, polis y política se presuponen, así como ciudad y ciudadanía" (Porto-Goncalves, 2002: 300).

14. Es interesante verificar cómo estas tecnologías se complementan. Chamayou (2015), sujetándose en el control "telearquico" (comando a distancia o telecomando sin cabo, como fue definido por BurnetHershey), afirma que "el dron y el muro funcionan juntos. Se articulan de forma coherente en un modelo de seguridad que combina cerramiento del espacio doméstico e intervención externa desprovista de cualquier involucramiento vital. El ideal de la fuerza telecomandada es perfectamente congruente con el de un Etado-burbuja" (p. 252) 
a Porto-Goncalves (2000), al apegarse a la polis como "límite" y a la política como "arte de definir límites" (p. 300)13 , es por perder su(s) límite(s) que el Estado -y con él, de cierta forma, la misma política, termina vaciándose, inclusive, en el sentido de construcción y/o mantenimiento del llamado espacio público o, de forma más amplia, de los espacios del bien común.

No se trata más, con todo, de privilegiar los (des)ordenamientos territoriales zonales, el control de la población por el control de áreas bien delimitadas, proceso inherente a la reproducción del Estado nación, que expandió por todo el mundo su inmensa colcha de retazos de pretendido poder exclusivo sobre parcelas territoriales no superpuestasy, preferencialmente, continuas. Los "límites" territoriales hoy, se dan también por el control de redes, de circuitos de movilidad, de rutas de circulación, en sentido estricto. Si seguimos la afirmación de Deleuze y Guattari (1996) de que también nos territorializamos por la repetición del movimiento, el comando de movimientos o flujos se convierte en una de las formas cada vez más evidente de control territorial. El control de la accesibilidad enfatizado por RobertSack (1986) en su definición de territorialidad produciendo territorios-zona, debe ser ampliada hacia el control de acceso, no sólo a las áreas sino también a redes, vías o circuitos de movilidad.

Y, ¿cómo, más allá de la definición de delimitaciones zonales, se controla una red? Se puede afirmar que este control se evidencia bajo dos formas principales:

a) el establecimiento de "represas" o barreras, con o sin monitoreo por cámarasy/o "Checkpoints" que nunca cubren todos los pasajes, por lo que estas barreras terminan dejando siempre la posibilidad de ser contorneadas, más vertical (vía satélites y "drones", por ejemplo) o más horizontalmente (vía muros y/o torres de control en lineas de fronteras) ${ }^{14}$;

b) la "canalización" de ejes o circuitos de circulación -que se puede dar tanto de forma más concreta con grandes vía elevadas o murosductos, como aquellos que protegen grandes arterias de tráfico (como la "Línea Roja", en Río de Janeiro), como de forma menos material, mediante el monitoreo de la movilidad con el uso de cámaras en espacio abierto o, de forma más directa, por medio de los datos biométricos o tobilleras electrónicas.

Podemos retomar aquí, el ejemplo de algunas favelas de Río de Janeiro, bastante ilustrativo de la ambivalencia de los "límites" -sean ellos más zonales o más reticulares en el control espacial de flujos de diversos órdenes. La política de las UPPS - Unidades de Policía Pacificadora- publicitada por el Estado como la gran salida para la cuestión de la violencia asociada al narcotráfico en las favelas cariocas, ha representado, efectivamente, la consolidación de un Estado de excepción (Agamben, 2004) policial o militarizado cuya intervención, propuesta como temporal, termina por convertirse en permanente. Diversos acontecimientos recientes ponen en jaque la eficacia de este modelo autoritario y totalizante -totalizante, tanto en el sentido más "vertical"de la acción jerárquica de la policía que, como en los toques de queda, aquí ya comentados, excede en mucho sus atribuciones formales, como en el sentido más "horizontal" que, en ausencia de políticas sociales efectivas que acompañen el proceso de característica militar, insertan la policía en áreas y cuestiones sociales más allá de las estrictas atribuciones a que está delegada.

En una clara confirmación de la máxima de Agamben (2013), de que la sociedad ("de seguridad") contemporánea desistió "de cualquier intento de dominar a las causas" y se dedica apenas a "gobernar los efectos", el mismo secretario de Seguridad del estado de Río de Janeiro, José Beltrame, frente a los efectos mitigados de la política "de ocupación" de las favelas, reconoce que el objetivo no era acabar con el narcotráfico sino "retomar sus territorios". Él sólo olvida reconocer que se trata de un tipo muy particular de territorio, el territorio-zona, cuyo dominio, cada vez más dispendioso por la necesidad de mantener un aparato militarizado, ya era cuestionado por el propio narcotráfico. Así, proliferan los territoriosred donde el dominio de puntos, o mejor, de conexiones estratégicas, especialmente para la comercialización de la droga, es la condición más relevante. Sin hablar de los narcotraficantes que se reterritorializaron "zonalmente" en áreas más periféricas de la ciudad o de la región 
metropolitana, donde se exacerban disputas por territorio entre diferentes bandas.

El límite así configurado, no pasa de una "barrera de seguridad" (o "cinturón", como lo denomina la propia Secretaría), bastante vulnerable en su constitución, que no establece una protección definitiva, pareciendo sólo postergar el problema o relegándolo a ciertas áreas de la ciudad. Este "cinturón de seguridad" privilegia a las zonas sur y centro, así como algunas áreas de la zona oeste y Barra de la Tijuca donde estarán localizados los eventos de los Juegos Olímpicos de 2016. Una de las cuestiones siempre planteada por la población local es, qué tipo de seguimiento tendrá el proyecto luego de la realización de los juegos y la crisis económica, con la reducción de los voluminosos recursos exigidos para su mantenimiento y/o expansión. En este caso, también verificamos la vinculación del proceso en un espacio-tiempo específico: hasta dónde y hasta cuándo las UPPs actuarán -como mera política militarizada (sin una real política social), como mera ocupación de áreas (sin control efectivo de las redes -locales, nacionales e internacionales- de drogas y de armas), y como simples paliativos o retrasadores de una situación mucho más compleja, abarcando la ambigüedad de los límites entre los circuitos legales e ilegales de la economía y del poder (tal como enfatiza Telles, 2010).

Es esta ambigüedad de los límites entre lo legal y lo ilegal lo que impregna hoy la misma constitución de la política "normal" del Estado, que recurre a lo que Agamben (2013) denomina "pequeños golpes de Estado", por apelar todo el tiempo a situaciones de emergencia que justifican la toma de medidas y el establecimiento de una "legalidad ilegal" excepcional. En el caso específico de las favelas de Río de Janeiro, este diseño es aún más intrincado, con agentes "legales", como la policía oficial del Estado, participando al mismo tiempo, de circuitos ilegales -no sólo al ser corrompida por la admisión del "arreglo" (pagamento) acordado con los traficantes, sino también por la actuación directa como una especie de "seguridad privada" en los diferentes grupos paramilitares(milicias) que se extienden por las periferias de la ciudad, en especial, en la zona norte.
Esto hace que gran parte de la región metropolitana de Río de Janeiro se encuentre hoy en una especie de ir-y-venir jurídico-político en el que diversos sujetos se suceden o se superponen en el control territorial, a modo de construir una territorialidad muy compleja y casi "sin límites", en el sentido de admitir todo tipo de límite, consecutiva o simultáneamente. Aunque volátiles -en términos de intercambio de banda criminal, por ejemplo- estos territorios mantienen, casi siempre la violencia y la represión, aunque temporal, a la misma movilidad de la mayoría de sus habitantes. Con todo, una marca territorial muy explícita y relativamente constante es la imprevisibilidad y/o la inseguridad. Justamente por estas características es que no se trata, como admite el sentido común, de "espacios cerrados" o "confinados". Lejos están de eso las favelas de Río de Janeiro -como muchas periferias metropolitanas de América Latina- son marcadas por una territorialidad múltiple, que va desde la presencia más explícita del Estado (a través de unidades policiales y escolares, por ejemplo) y del poder local del narcotráfico, hasta redes globales de articulación de ciertos movimientos populares.

Sólo para finalizar con un ejemplo muy concreto, un habitante de una de las favelas más conmocionadas de la zona norte de Río de Janeiro que visitamos, participa, o mejor dicho, transita por una multiterritorialidad que incluye: empleo en una empresa pública del Estado de Río de Janeiro (lo que le exige circular cerca de 30 kilómetros diarios hacia el trabajo en el área central de la ciudad); participación en una entidad ligada a movimientos populares que tienen actuación, al mismo tiempo, en la misma favela y en varios estados de Brasil (lo que, ocasionalmente, lo lleva a viajar hacia otros estados); y la relación (aunque eventual) con representantes del poder local ligado a una facción del narcotráfico (que, a su vez, está articulada nacional e internacionalmente, a través de los circuitos de armas y drogas).

Como se puede observar, mucho más que límites espacio-temporalmente bien demarcados, vivimos hoy, principalmente en las periferias urbanas, una sobreimposición y vinculación intrincada de poderes de tal orden, que sería más 
adecuado hablar de una transterritorialidad -el tránsito frecuente, compulsivo o voluntario, por distintas territorialidades. El reconocimiento de la relevancia de este tránsito me llevó a utilizar la expresión "vivir en el límite", que dio título a un libro (Haesbaert, 2014). Allí exploré la doble connotación del término:

...pues envuelve el sentido contradictorio de estar en una situación, al mismo tiempo, de impulso y exceso, y de fragilidad y riesgo. Pero, impulso para asumir riesgos significa también desafío, antesala de lo nuevo -mejor o peor, pero que implica buscar, arriesgar. En una perspectiva más geográfica, ya que la metáfora del límite/frontera está siempre ubicada, podemos afirmar que adquiere otra doble connotación: vivir en el umbral de un espacio, traspasando sus fronteras -o vivir en y a través de ellas- y vivir rehaciendo, reconstruyendo o reponiendo límites, vistos concomitantemente como final y (re) comienzo (2014: 298-299).

Este ir-y-venir entre diferentes territorios traspasando límites tiene, obviamente, una connotación que puede ser tanto positiva como negativa, pues, cuando es obligada, reduce drásticamente el carácter libertario que potencialmente carga en sí misma. Estar en movimiento y transitar por diversos territorios no es, por tanto, sinónimo de mayor autonomía y libertad. HannaArendt (2004) Ilega a afirmar igualmente que (para bien o para mal, añado), "los cuerpos políticos siempre fueron proyectados con vista a la permanencia y sus leyes siempre fueron comprendidas como limitaciones impuestas al movimiento" (p. 56). Esta constatación nos hace recordar la distinción, muchas veces necesaria, entre el uso político o normativo de la categoría "límite", el uso por el sentido común, envuelto en actividades prácticas, cotidianas, y el uso analítico, a veces cuestionado, como vimos al inicio de este artículo. Frente a las críticas al "límite" analíticamente reconocido como línea demarcadora que tendría siempre un carácter arbitrario, Hissa dirá que se trata de "un concepto inventado para dar sentido a las cosas, para facilitar la comprensión de lo que puede ser interpretado de diversas maneras" (2002: 21). Raffestin, por su lado, cuestiona de forma más incisiva:

No hay nada más absurdo que escuchar decir que todo sistema de límites es arbitrario. Sin duda, todo sistema de límites es convencional, ya que desde el momento en que fue pensado, colocado en el lugar y que funcione, él deja de ser arbitrario, pues, facilita el encuadramiento de un proyecto social, aquel propio de una sociedad. (...) los límites sólo manifiestan un proyecto que por sí mismo no es arbitrario, pues, eso sería admitir que la clase dominante no procura encuadrar su proyecto social y comunicarlo bajo una forma ideológica (Raffestin, 1993: 165-166).

De cualquier modo, así condenemos líneas limitadoras por no existir exactamente como tales en la realidad, jamás podremos ignorar los diversos usos -inclusive ideológicos- que de ellas son hechos. Como afirmé en otro momento, "más que preguntarnos sobre la 'realidad' de estos recortes [límites], debemos indagar para qué sirven -lo que hacemos con ellos-y/o cuáles son sus efectos, especialmente políticos" (Haesbaert, 2014: 121)15. Efectos que están profundamente impregnados de historicidad, pues, "todo periodo de crisis, toda insurrección, toda revolución, se traducen por modificaciones más o menos fuertes en los sistemas de límites" (Raffestin, 1993: 170). Para retomar conclusivamente el debate inicial sobre la relación entre límites y espacio-tiempo, reproduzco otra proposición de Raffestin:

... el límite o la frontera no deriva solamente del espacio, sino también del tiempo. De hecho, la cuadrícula no es exclusivamente territorial, es también temporal, pues, las actividades que son

15. En este mismo trabajo, de modo provocativo, fue hecha una breve relectura de la linea limítrofe a la luz de la "metáforaconcepto" de la "vuelta", en el sentido propuesto por Deleuze, para quien "lo múltiple no es sólo lo que tiene muchas partes, sino que es múltiple de muchas maneras" (apud Haesbaert, 2014: 122). Ver el límite más que como una linea como una vuelta, significa trabajar al mismo tiempo con las ideas de continuidad y discontinuidad espacial, tratando el espacio no como mera superficie bidimensional, sino como un compuesto denso de tres dimensiones (sin hablar de la "cuarta", que es el tiempo).

16. Entre los diverssos trabajos recientes sobre el papel de los muros fronterizos ver, por ejemplo, Brown (2009) y Rosière (2015). 
reglamentadas, organizadas y controladas se expresan de una sola vez, en el espacio y en el tiempo, en un lugar y en un momento dados, sobre una cierta extensión y por una cierta duración (1993: 169).

Un claro ejemplo de refuncionalización espaciotemporal de barreras fronterizas es lo que ocurre hoy con diversos muros, más antiguos o más recientes; de la muralla China y del muro de Adriano (en el norte de Inglaterra) al muro entre las dos Coreas, muchos de ellos con un papel mucho más simbólico que material ${ }^{16}$. Termino entonces por afirmar, que el discurso del "fin" de las fronteras o de los límites debe ser cuestionado, no sólo por la ideología neoliberal contemporánea que lo legitima, sino también porque la cuestión no envuelve sólo a laslineas demarcadoras y barreras en sí mismas sino, sobre todo, al sentido político espacio-temporalmente diverso de estos límites -a quién y para qué sirven-. Como argumentan von Houtum et al. (2005), recordando a Latour, la presencia de una llave en la mano puede transformar una puerta en un simple paso o, al contrario, en una barrera intraspasable. De la misma forma, un muro puede significar protección para unos y un insulto o una provocación para otros.

Raffestin dirá que, "siendo 'convencionales'", las divisiones, clasificaciones y/o delimitaciones "no siempre son satisfactorias desde el punto de vista existencial" y es por esto que "todo cambio de la malla [territorial] implica una nueva estructura de poder (1993: 170). En este sentido, si nuestra lucha es por territorios mucho más autónomos y de libertad, que den cuenta de nuestra existencia en un sentido más amplio, esto implica considerar no el fin de los límites y/o fronteras, sino el establecimiento de una otra modalidad de malla territorial, de "territorios cuyas demarcaciones, a pesar de establecer límites, distinciones (reconociendo nuestra multiplicidad), permanezcan lo suficientemente flexibles para ser reevaluados, reconstruidos y reubicados siempre que una nueva configuración socio-política más democrática y justa lo demande" (Haesbaert, 2014: 298). En otras palabras,

La lucha concreta implica que cada grupo (...) tenga la capacidad, la autonomía y la libertad para abrir o cerrar (en otras palabras, bien o mal, delimitar) su territorio cuando así lo juzguen necesario. Tal vez pudiésemos afirmar, que el territorio (...) autónomo será aquel en el que tenemos efectivo poder para abrirlo y/o cerrarlo cuando así, libremente, decidimos, sin que eso afecte negativamente la vida de aquellos que están a su alrededor (Haesbaert, 2014: 123).

Es a través de este juego, al mismo tiempo espacial y temporal de los límites, variable conforme la historia y la geografía de cada grupo social, que se diseñan las múltiples posibilidades de construcción de una efectiva y múltiple autonomía territorial. Pero, este ya es tema para otro intenso debate -que permanezca, entonces, la provocación para desarrollos futuros.

\section{Referencias}

Agamben, G. (2013). Por uma teoria da política instituinte.. Disponível em: http://www.revistapunkto. com/2015/05/por-uma-teoria-da-potencia-destituinte.html (acessado em 20.12.2015)

Estado de Exceção. São Paulo: Boitempo, 2004.

Arendt, H. (2004). A Condição Humana. Rio de Janeiro: Forense Universitária.

Braudel, F. (1946). O Mediterrâneo e o mundo mediterrânico na época de Felipe II. Lisboa: Martins Fontes.

Brown, W. (2009). Murs: les murs de separation et le déclin de la souveraineté. Paris: Les Prairies Ordinaires. 
Cassey, E. (1997). The fate of place: a philosophical history. Los Angeles: California University Press.

Cataia, M. (2010). Fronteiras: territórios em conflitos. Geografia em questão v. 3, n. 1 (disponível em: http://e-revista.unioeste.br/index.php/geoemquestao/issue/view/350/showToc)

CHAMAYOU, G. Teoria do Drone. São Paulo: Cosac Naify, 2015.

Creswell, T. (2006). On the move: mobility in the modern western world. Nova York: Routledge.

Deleuze, G. (1990). "Post-Scriptum" sobre as sociedades de controle. In: Conversações. São Paulo: Ed. 34.

Deleuze, G. e Guattari, F. (1996) Mil Platôs. São Paulo: Ed. 34.

(1972) O Anti-Édipo: capitalismo e esquizofrenia. Lisboa: Assírio \& Alvim, s/d.

Foucault, M. (2008). Segurança, território e população. São Paulo: Martins Fontes.

(2001). Of other spaces. Diacritics V, In: Ditos e Escritos III: Estética - literatura e pintura, música e cinema. Rio de Janeiro: Forense Universitária.

Microfísica do Poder. Rio de Janeiro: Graal, 1979.

Grataloup, C. (2006). Os períodos do espaço. GEOgraphia, v. 8, n. 16.

(1191).Les régions du temps. En: Périodes. La construction du temps historique. Paris: Ed. da Ehess e Histoire au Présent.

Grossberg, L. (1196). The space of culture, the power of space. In: Chambers, I. e Curti, L. The PostColonial Question: common skies, divided horizons. Londres e N. York: Routledge.

Haesbaert, R. (2004). O mito da desterritorialização: do "fim dos territórios" à multiterritorialidade. Rio de Janeiro: Bertrand Brasil.

. (2014). Viver no limite: território e multi/transterritorialidade em tempos de in-segurança e contenção. Rio de Janeiro: Bertrand Brasil.

Harvey, D. (1994). The social construction of space and time: a relational theory. Geographical review of Japan, v. 67, n. 2, 126-135.

(2006). O espaço como palavra-chave. GEOgraphia v. 14, n. 28.

Heidegger, M. (2006). Bâtir habiter penser. In: Essais et conférences. Paris: Gallimard.

Hissa, C. (2002). A mobilidade das fronteiras: inserções da geografia na crise contemporânea. Belo Horizonte: Ed. UFMG.

Klein, N. (2008). A doutrina do choque: a ascensão do capitalismo de catástrofe. Rio de Janeiro: Nova Fronteira, 
Lacoste, Y. (1988). A Geografia, isso serve, em primeiro lugar, para fazer a guerra. Campinas: Papirus. Machado, L. (1998) Limites, fronteiras, redes. In: Strohaecker, T. et al. (org.). Fronteiras e Espaço Global. Porto Alegre: AGB, 1998.

Martins, J. (1997). Fronteira: a degradação do Outro nos confins do humano. São Paulo: Hucitec.

Massey, D. (2008). Pelo Espaço: por uma nova política da espacialidade. Rio de Janeiro: Bertrand Brasil.

(1994). Space, Place and Gender. Minneapolis: University of Minnesota Press.

Merleau-Ponty, M. (1999). Fenomenologia da Percepção. São Paulo: Martins Fontes.

Porto-Gonçalves, C. (2002). Da geografia às geo-grafias: um mundo em busca de novas territorialidades. In: Ceceña, A. e Sader, E. (org.) A guerra infinita: hegemonia e terror mundial. Buenos Aires: Clacso.

Raffestin, C. (1993) Por uma Geografia do poder. São Paulo: Ática.

Rancière, J. (2003) O princípio da insegurança. Folha de São Paulo, 21 de setembro.

Rosière, S. (2015). Mundialização e teicopolíticas: análise do fechamento contemporâneo das fronteiras internacionais. Boletim Gaúcho de Geografia v. 42, n. 2, 369-388.

Sack, R. (1986), Human territoriality. Cambridge: Cambridge University Press.

Santos, M. (1996). A natureza do espaço. São Paulo: Hucitec, 1996.

Telles, V. (2010). A cidade nas fronteiras do legal e do ilegal. Belo Horizonte: Argvmentvm.

Turner, F. (2004) O significado da fronteira na história americana. In: Knauss, P. (org.) Oeste americano: quatro ensaios de história dos Estados Unidos da América. Niterói: EdUFF.

Von Houtum, H., Kramsch, O. e Zierhofer, W. (2005) Prologue. In: B/ordering Space. Aldershot e Burlington: Ashgate, 2005.

\section{Notas al final}

1. Artículo publicado originalmente bajo el título "Limites no espaço-tempo: A retomada de um debate" en la Revista Brasileira de Geografia, v. 61 n. 1 (2016). Traducción realizada por José Quintero Weir (Universidad Autónoma Indígena), revisión final hecha por Alexander Panez Pinto (Universidad del Bio-Bio) 